\title{
To study the prevalence of cutaneous manifestationsin newborns and its correlation with defined maternal and neonatal factors
}

\author{
Kurrey VK ${ }^{1}$, Phuljhele $\mathbf{S}^{2}$, Jain $\mathbf{Y}^{3}$ \\ ${ }^{1}$ Dr Virendra K. Kurrey, Associate Professor, Department of Paediatrics, ${ }^{2}$ Dr Sharja Phuljhele, Professor and Head, \\ Department of Pediatrics, ${ }^{3}$ Dr Yavnika Jain, Post Graduate Fellow, Department of Pediatrics, All are affiliated with \\ Pt. J.N.M. Medical College Raipur, Chhattisgarh, India.
}

Address for Correspondence: Dr Yavnika Jain, Email: jainyavnika@gmail.com

\begin{abstract}
Introduction: Newborn skin may look and feel different, depending on the gestational age. Skin manifestations are common in neonates and cause parental anxiety. Many of these are transient and physiological, but some may require further workup to rule out a more serious disorder. Hence, it is of utmost importance for pediatricians and dermatologist to recognize these physiological states in neonates. Objectives: To study incidence of cutaneous manifestations in new born and its correlation with defined maternal and neonatal factors. Material \& Methods: Institution based, observational, cross sectional cohort study was conducted in Post natal ward of Dr. B.R.A.M. Medical College, Raipur, C.G. Total 4000 neonates were taken in to study. All the neonates irrespective of gestation, up to 3 days of life were included in study, with or without significant maternal history. Detailed dermatological examination was conducted. Obtained data was analyzed by appropriate statistical method. Observation: In all, we studied 18 skin lesions- Epstein pearl 3323 cases (83\%), Mongolian spot 2828 cases $(70.7 \%)$, milia 1344 cases $(33.6 \%)$, sebaeceous gland hyperplasia 1237 cases $(30.9 \%)$, erythema toxicum neonatorum 711 cases $(17.8 \%)$, occipital alopecia 648 cases $(16.2 \%)$, lanugo 575 cases $(14.4 \%)$, icterus 548 cases $(13.7 \%)$, physiological scaling $482(12.1 \%)$, vernix caseosa 9.8\%, acrocyanosis $8.6 \%$, salmon patch $7.1 \%$, miniature puberty $6.9 \%$, caput succedaneum $1.6 \%$. Conclusion: In India, Epstein pearl and Mongolian spot are predominant skin lesions. Distribution profile of skin lesions is affected by interracial, environment and hormonal factors.
\end{abstract}

Key words- Epstein pearl, Mongolian spot, Erythema toxicumneonatorum, Sebaceous gland hyperplasia.

\section{Introduction}

Skin manifestations in newborns are common and can cause anxiety in parents. Many are transient and physiological, but some may require further work up to rule out pathological nature of lesion. So it is of utmost importance to a pediatrician as well as dermatologist, to recognize physiological states that can present in a normal neonate. Development of skin structures takes place from primitive embryonic tissues in a sequential manner. As most of the development is complete by 24 weeks, but functional maturity is only achieved till term [1] and post-natal age play a very important role in manifestation of skin lesion [2]. Skin manifestations depend on various maternal and neonatal factors. Maternal factors include - race and geographic location,

Manuscript received 20 $0^{\text {th }}$ April 2016

Reviewed: $2^{\text {nd }}$ May 2016

Author Corrected: $14^{\text {th }}$ May 2016

Accepted for Publication $27^{\text {th }}$ May 2016 any medical illness, history of drug ingestion, parity, mode of delivery, socio-economic status, hygiene. Neonatal factors include - age, sex, gestation, heredity and race. Hence, it is of worth to analyze these conditions to understand the spectrum that affect the newborns. Neonatal skin may look and feel different depending on gestation age of new born [3]. Rashes are commonly seen in first month of life, which affect usually $80 \%$ of children [4]. By understanding stages of development we can come to know about the critical periods when the skin is susceptible to developmental errors, expression of genetic skin disease at the earliest, prenatal diagnosis of genodermatoses by using skin samples [5, 6]. About various skin lesions found commonly-Vernix caseosa is a protective biofilm covering the fetus during last trimester. Vernix and epidermal barrier lipids appear to share protective 
functions for fetal and neonatal skin [7]. Harlequin color change-describes a sharply described erythema that develops on dependant half of body, when neonate is in left lateral decubitus position. Hyper pigmented lesions at birth can be various. [8]. Epidermal melanocytic lesions includes café au lait macules. Dermal melanocytosis includes Mongolian spots. Among vascular birth marks - salmon patch and port wine stain are common. Caput succedaneum is formed mainly during prolonged second stage of labor, presenting part of scalp becomes edematous [9].

Cephalohematoma-results due to bleeding at subperiosteal region, rupture of diploic veins is the reason of bleed. Sebaceous gland hyperplasia appears as numerous small pinpoint yellow to white papules involving the nose, upper-lip and malar areas.

Maternal androgens enlarge the pilosebaceous glands. Milia are common, discrete yellow-white papules that are slightly larger than those seen in sebaceous gland hyperplasia and represent tiny epidermal inclusion cysts. Epstein pearl is one the commonest conditions found, mainly on palate and alveoli. Erythema toxicum neonatorum is common benign condition, not present since birth, but appear within first 2 days of life and continue to appear for the first 3-4 weeks of life.

One of the studies was that of K. L. E. university by Haveri and Inamadar [10], performed in deptt. of dermatology, results showed that sebaceous gland hyperplasia $(89.4 \%)$, epstein pearl $(89.1 \%)$, mongolian spot $(84.7 \%)$, knuckle pigmentation $(57.9 \%)$, lineanigra $(44.7 \%)$, hypertrichosis $(35.3 \%)$, miniature puberty $(13.3 \%)$, acrocyanosis (30.9\%), physiological scaling $(10.8 \%)$ and vernixcaseosa $(7.7 \%)$ were common. One study was done in Amritsar by Kaur and Sachdeva [11] most common lesion was Epstein pearl (61\%), followed by Mongolian spot $(60.2 \%)$, superficial cutaneous lesions $(40 \%)$ icterus $(25.6 \%)$, sebaceous gland hyperplasia $(21.4 \%)$, milia $(23.8 \%)$. Erythema toxicum neonatorum was the most common transient noninfective lesion with $21 \%$.

So our aim was to study the clinical profile of various skin lesions in early neonatal period in newborns in Chhattisgarh. Compared to west data, literature available for Indian scenario is relatively meager.

\section{Material and Methods}

Study Design - hospital based, prospective, analytical study. Place of study was-department of pediatrics and department of obstetrics and gynecology at Dr. B. R. A. M. Hospital, Raipur, Chhattisgarh. duration of study- 18 months (from April 2014 to September 2015). The inclusion criteria were -1. Live births delivered in Dr. B. R. A. M. Hospital, within 3 days of life. 2. Preterm $(>=1.7 \mathrm{~kg})$, term and post term babies. 3. Neonates with consent taken from mother. 4. Neonates born to mothers with significant maternal illness like eclampsia, seropositive status diabetes, hypo/hyperthyroidism, sickle cell disease. The exclusion criterion was 1 . Babies with ambiguous genitalia.

Ethical Clearance- It was taken from ethics committee, Pt J N M Medical college and associated Dr B R Ambedkar Hospital Raipur. Data collection was done by taking into account the neonates delivered in our hospital, meeting the inclusion criteria. Informed consent was taken from mothers. Daily rounds were taken in post natal wards and skin lesions were noted in each and every child. Each neonate was observed for maximum of 3 days.

Detailed examination of nails, skin, hair, genitals, oral cavity, scalp and whole body was done in order to record the physiological and pathological cutaneous manifestations in the newborns. In addition to it, maternal history as gravida, maternal illness, mode of delivery was noted along with neonatal history revealing sex of the child, post natal day and birth weight. No investigations were done.

Sample size was calculated using formula- $4 \mathrm{PQ} / \mathrm{L} 2$, where $-\mathrm{P}=$ prevalence of skin lesion, $\mathrm{Q}=1-\mathrm{P}, \mathrm{L}=\mathrm{Level}$ of error, Confidence level=95\% Taking $\mathrm{P}=80 \%, \mathrm{~L}=5 \%$, we see that minimum sample size $=256$. We have taken 4000 .

Statistical Analysis- All the observations were recorded and statistical analysis was done using computerized program SPSS version 21. Chi square test with $\mathrm{p}$ value and Odds ratio was calculated. Chi square test provides a method of testing the significance of difference between 2 proportions or groups.

Odds Ratio- is a measure of strength of association between risk factor and outcome. 


\begin{tabular}{|l|l|l|}
\hline Factor & Manifestations \\
\hline & Yes & No \\
\hline Factor present & A & B \\
\hline Factor absent & C & D \\
\hline
\end{tabular}

Cross-product ratio/Odds ratio $=\mathrm{a} * \mathrm{~d} / \mathrm{b} * \mathrm{c}$

\section{Results}

In our study, sample size taken is 4000. Total male newborns in study were $2323(58.1 \%)$ and total female 1677 (41.9\%). Term infants form the majority 3357 (83.9\%), followed by pre term $583(14.5 \%)$ and post term 60 (1.5\%). Total number of newborns with birth weight $<2 \mathrm{~kg}$ are $1063(26.5 \%)$, between $2-2.499 \mathrm{~kg}$ are $1266(31.6 \%)$ and greater than or equal to $2.5 \mathrm{~kg}$ are $1671(41.7 \%)$. Further we see that total number of patients delivered vaginally (NVD) are 3014, caesarean section 944, forceps delivery are 33, breech 9. History of consanguinity was found in 191 mothers, rest 3809 did not have any such history. Majority of mothers did not have any sort of major medical illnesses, accounting to 3871 . Medical illnesses taken into account are Diabetes mellitus (18), eclampsia (23), hypertension (23), hypothyroidism (12), sero positive status (21), sickle cell disease (32).

Table 1: Sex wise distribution of skin lesion.

\begin{tabular}{|l|l|l|l|l|}
\hline Lesion & Female & $\mathbf{\%}$ & Male & \% \\
\hline Mongolian Spot & 1205 & 71.9 & 1623 & 69.9 \\
\hline Epstein Pearl & 1400 & 83.5 & 1923 & 82.8 \\
\hline Sebaeous Gland Hyperplasia & 522 & 31.1 & 715 & 30.8 \\
\hline Milia & 569 & 33.9 & 775 & 33.4 \\
\hline Erythema Toxicum Neonatorum & 300 & 17.9 & 411 & 17.7 \\
\hline Occipital Alopecia & 255 & 15.2 & 393 & 16.9 \\
\hline Lanugo & 266 & 15.9 & 309 & 13.3 \\
\hline
\end{tabular}

Other Lesions: physiological scaling female 242 (14.4\%,) male 240, (10.3\%). Acrocyanosis female 139 (8.3\%), male $204(8.8 \%)$, salmon patch female $112,6.7 \%$, male 170, 7.3\%., miniature puberty female $140,8.3 \%$, male $137,5.9 \%$, cutis marmoratus female $16,1.0 \%$, male $19,0.8 \%$, icterus female $217,12.9 \%$, male $331,14.2 \%$, caput succaedaneum female $32,1.9 \%$, male $31,1.3 \%$, harlequin color change female $13,0.8 \%$, male $13,0.6 \%$,café au lait spot female 26 , $1.6 \%$, male $30,1.3 \%$. congenital menalocytic nevi female $21,1.3 \%$, male $36,1.5 \%$, vernixcaseosa female $200,11.9 \%$, male $192,8.3 \%$.

Table 2: Gestation wise distribution of lesions.

\begin{tabular}{|l|l|l|l|l|l|l|}
\hline Lesion & Preterm & $\mathbf{\%}$ & Term & \% & Post Term & \% \\
\hline Mongolian spot & 300 & 51.5 & 2479 & 73.8 & 49 & 81.7 \\
\hline Epstein pearl & 468 & 80.3 & 2805 & 83.6 & 50 & 83.3 \\
\hline Lanugo & 556 & 95.4 & 19 & 0.6 & 0 & 0 \\
\hline Sebaceous gland hyperplasia & 98 & 16.8 & 1124 & 33.5 & 15 & 25 \\
\hline Occipital alopecia & 80 & 13.7 & 539 & 16.1 & 29 & 48.3 \\
\hline Icterus & 85 & 14.6 & 461 & 13.7 & 2 & 3.3 \\
\hline Milia & 98 & 16.8 & 1241 & 37 & 5 & 8.3 \\
\hline
\end{tabular}

Other skin lesion (in percentage) respectively in preterm ,term and post term babies-physiological scaling- 1.2, 12.5, 93.3, acrocyanosis 5.8, 9.1, 3.3, salmon patch 6.5, 7.2, 1.7, miniature puberty $0.3,7.3$, 50, ETN- 3.9, 20.3, 8.3, cutis marmoratus $2.7,0.5,5$, caput $0,1.9,0$, harlequin color change-3.8, $0.1,0$, café au lait spot- $0.5,1.5,3.3$, vernix caseosa$3.3,11.1,0$, congenital melanocytic nevi-0.5, 1.5, 3.3. 
Table 3: Association of various maternal and neonatal factors with occurrence of specific skin lesion.

\begin{tabular}{|c|l|l|l|l|l|}
\hline S. No. & Skin Lesion & Factor & P value & Odds Ratio & Conf. Interval \\
\hline 1. & Epstein pearl & Birth weight & $=0.031$ & 1.2 & $1.01-1.4$ \\
\hline 2. & Epstein pearl & Parity & $=0.0012$ & 1.32 & $1.1-1.52$ \\
\hline 3. & Miniature puberty & Sex & $=0.03$ & 1.4 & $1.1-1.8$ \\
\hline 4. & Miniature puberty & Birth weight & $<0.001$ & 0.47 & $0.37-0.68$ \\
\hline 5. & Miniature puberty & Gestation & $<0.001$ & 0.039 & $0.01-0.15$ \\
\hline 6. & Lanugo & Gestation & $<0.001$ & 3682.8 & $2033.9-6668.4$ \\
\hline 7. & Lanugo & Birth weight & $<0.001$ & 53.2 & $23.3-84.1$ \\
\hline
\end{tabular}

Table 4: Showing the comparative study among various races of world $[10,11,12,13,14,16,20,23,24]$

\begin{tabular}{|c|l|l|l|l|l|l|}
\hline S. No & Race & EP & Mong Spot & SGH & MILIA & ETN \\
\hline 1. & Indian & $45-90 \%$ & $70-90 \%$ & $20-80 \%$ & $20-40 \%$ & $25 \%$ \\
\hline 2. & Caucasians & $35 \%$ & $62 \%$ & $47 \%$ & - & $37 \%$ \\
\hline 3. & Japanese & - & $81.5 \%$ & - & - & $40.8 \%$ \\
\hline 4. & Chinese & - & $86.3 \%$ & - & - & $33.7 \%$ \\
\hline 5. & Iranian & $70-88 \%$ & $70-80 \%$ & $43.7 \%$ & $7.5 \%$ & $12-54 \%$ \\
\hline 6. & Turkish & - & $13.2 \%$ & $31.8 \%$ & $1.4 \%$ & $30.9 \%$ \\
\hline 7. & Australian & $56 \%$ & $25.5 \%$ & $48 \%$ & $36 \%$ & $34.8 \%$ \\
\hline 8. & Black & $29.1 \%$ & $86.6 \%$ & $28.2 \%$ & - & $11.6 \%$ \\
\hline
\end{tabular}

1. Epstein pearl, mongolian spot, milia, sebaceous gland hyperplasia are the commonest skin lesions in newborn period.

2. Racial, environmental and hormonal factors do play an important role in manifestation of variety of skin lesions.

3. Male newborns and term babies were found to be maximum in our study.

4. Skin lesions were found to be more in $<2.5 \mathrm{~kg}$ babies, $\mathrm{P}<0.001,[<2.5 \mathrm{~kg} \mathrm{vs}>2.5 \mathrm{~kg}$, significant, $\mathrm{OR}=13.05$,C.I. $=8.01-21.1$ (Table-3)

5. Skin lesions were more common in preterm babies, $\mathrm{P}<0.001$, [preterm vs term], significant, $\mathrm{OR}=16.05, \mathrm{C} . \mathrm{I}=3.9-64.8$.

6. Parity and maternal illness was not found to be significantly associated with the skin manifestations.

7. Significant association with sex of the child miniature puberty found more in females, Vernix caseosa more in males, lanugo more in male newborns. (Table-3)

8. Significant association with birth weight: In erythema toxicum neonatorum, low birth weight was found to be protective against it, Epstein pearl more in $<2.5 \mathrm{~kg}$, Miniature puberty more in $>2.5 \mathrm{~kg}$ babies, Lanugo more in $<2.5$ $\mathrm{kg}$. In case of Mongolian spot, low birth weight was found to be protective. (Table-3)

9. Significant association with gestation: Miniature puberty was found more in term and post term babies, Lanugo more in preterms, Vernix caseosa more in term and post terms, Sebaceous gland hyperplasia more in term and post term babies, Milia more in term and post term babies, in Mongolian spot low birth weight was found to be protective. Erythema toxicum neonatorum, more in term and post term babies. (Table-3)

10. Physiological scaling was found more in term and post term babies. (p value $<0.001)$. (Table- 3 )

11. In dark races, Mongolian spot is more common and in fairer races salmon path is common along with Epstein pearl. (Table-4)

12. Less occurrence of erythema toxicum neonatorum in our study is attributed to the fact that some of the newborns could'nt be observed till 3 days of age due to the early discharge of mother.

13. Patients developing erythema toxicum neonatorum, have chances of developing atopic dermatitis, so biannual follow up should be done in those cases.

14. Cases of congenital melanocytic nevi should be followed up closely to rule out chances of malignant transformation.

15. Fetal skin biopsy has crucial role in identifying the genetic skin diseases with reasonably high levels of safety and confidence. 


\section{Discussion}

Most common lesions found in our study were Epstein pearl, Mongolian spots, milia and sebaceous gland hyperplasia, these results were comparable to earlier studies carried worldwide. Epstein Pearl- Like our study (Epstein pearl-83.1\%), Kaur et al and Nanda et al also found Epstein pearl as the most commonly occurring skin lesion [11,12]. In Iranian study by Moosavi and Hosseini (2006) [13], Epstein pearl was found to be $70.2 \%$, Turkish study by Gokdemir et al (2009) [14], showed its occurrence as $58.76 \%$. Another Indian study by Haveri and Inamadar (2014) [10], showed frequency of Epstein pearl as $89.1 \%$. These are common in Caucasian infants. Maximum cases found to be significantly associated with birth weight less than 2.5 $\mathrm{kg}$ and with multiparous females. Though in the study of Kaur and Sachdeva (2002) [11] its prevalence was more in $>2.5 \mathrm{~kg}$ infants, which is contrary to our study. No significant relation was found with gestation, route of delivery or consanguinity.

Mongolian Spot has shown inter racial difference. Though In our study its prevalence is $70.7 \%$ which is comparable to earlier mentioned studies, its frequency is seen to be as high as $80-90 \%$ in Asians as found by Dash et al (2000) [15] and Hidano et al (1986) [16] and as low as $3-10 \%$ in Caucasians as described by Shih I H et al (2007) [17] and Ferahbas et al (2009) [18]. Its prevalence in India varies as $60-90 \%$ as shown by studies of Sachdeva and Kaur et al (2002) [11], Nanda and Kaur et al (1989) [12].

Most common site is sacrococcygeal region followed by buttocks and back, shoulders and extremities. Most commonly, Mongolian spots occurred in term or post term babies, and low birth weight was found to be protective against it. In Israeli study carried out by Kahana et al (1995) [19], showed the occurrence of Mongolian spots as $11.85 \%$ of Arabs and $6.65 \%$ of Jews. Orientals ranging from $74 \%$ to $84 \%$ $[16,20,21,22,23]$. A theory of origin of Mongolian spots in the Caucasians, explains its presence by the invasion from Asia of the Mongols. Another theory states that it first originated from Negroes in Africa and from them spread to the Mongols and Caucasians race.

Milia was found to be $33.6 \%$, similar to that of Kaur and Sachdeva (2002) [11], where, incidence was $23.8 \%$ and Kaur and Nanda (1989) [12], where incidence was $34.9 \%$.
Sebaceous Gland Hyperplasia accounting to about $30.9 \%$. Sebum secretion is higher in neonates than adolescents; it is due to the transfer of maternal androgen especiallly dehydroepiandrosterone, through placenta. Its incidence was similar to that found out by earlier Indian studies $[11,12,15]$. Study by Gokdemir et al (2009) [14] and Haveri and Inamadar (2014) [10], showed very high occurrence of this lesion. Its occurrence was more in male newborns and those weighing less than $2.5 \mathrm{~kg}$ but was not statistically significant. Relation to gestation was found significant, showing significant presence in term and post term babies, contrary to earlier study,1989 [12].

Another lesion present was Erythema Toxicum Neonatorum, with $17.8 \%$, similar to various earlier studies $[10,11,12]$. It was seen commonly after day 2 . Its prevalence varies among different racial groups $[13,16,18,20,24]$. It is most commonly seen in Caucasians (37.8\%) [25]. In a study conducted in Jordan by A Dahiyat (2006) [26], erythema toxicum neonatorum was found to be $68 \%$ inblack skinned people. Its occurence in our study was found significant with respect to gestation and birth weight. Earlier studies found that erythema toxicum neonatorum was less commonly associated with preterms and low birth weight, similar to our study.

Occipital Alopecia was $16.2 \%$ in our study, similar toearlier study (2002) 10. It was found maximally in male newborns, term babies and vaginally delivered newborns. Lanugo showed the occurrence of $14.4 \%$ in our study similar to earlier study [11,27] with male preponderance. Highest number was recorded in preterms, very few in terms and none in post term. All results with respect to sex, gestation and birth weight were found significant. Icterus was found to occur as $13.7 \%$, with male preponderance, more in term babies followed by preterm and post term newborns. Physiological Scaling was seen in $12.1 \%$ cases, similar toearlierstudy [10]. In other studies it was recorded higher 40\% in Kaur and Sachdeva (2000) [11] and $65 \%$ in Rivers et al (1990) [20]. It occurred almost in equal number in male and female newborns, mainly in term newborns, but occurred in almost all postdated newborns. Relation was significant. Very few cases were seen in preterms (they were preterm-Iugrbabies) as were in study by Haveri et al (2014) [10]. It is contrary to study conducted by Dash et al (2000) [15] and Moosavi and Hosseini (2006) [13] where it was not 
seen in preterms. Very few cases can be attributed to the fact that it was mainly because the duration of observation in our study was 3 days (much less than 4 weeks, the time when permeability barrierof preterm neonates undergoes maturation.) Vernix Caseosa had occurrence of $9.8 \%$, similar to earlier Study [10] with almost equal distribution in males and females, maximally occurring in normal vaginally delivered new borns, with highest number in term babies, followed by preterm and none in postdated newborns. Acrocyanosis was $8.6 \%$ in occurrence similar to earlier study [11], mainly occurring in males, term babies and vaginally delivered newborns.

Salmon Patch showed the occurrence of $7.1 \%$, with male preponderance (contrary to female dominance in Japanese study.) and occurred maximally in term babies, delivered vaginally. Its incidence is $28.4 \%$ in Indian study (1989) [12], in Japanese study (1986) [16] it was $22.3 \%, 27.8 \%$ in Taiwanese study (2007) [17], $18.78 \%$ in Jews, $19.97 \%$ in Arab neonates(1995) [19]. 15 cases of hemangioma were also present, found on leg and arm.

Congenital Melanocytic Nevi had occurrence of $1.4 \%$. In earlier studies $[11,13,16,17,20,28,29,30,31]$, it showed the range of 0.4 to $15.6 \%$,with the maximum cases occurring in dark babies [25]. Location was trunk mainly. All were less than $2 \mathrm{~cm}$. A study was undertaken by Kahana et al in Israel (1995) [19], which showed $0.35 \%$ Jewish infants to have congenital melanocytic nevi and $0.84 \%$ of Arabs, which was comparable to some previous studies. Arabs had greater number of melanocytic brown lesions (Mongolian spots, congenital melanocytic lesion and café au lait spots) than Jews descending from European society. Café au lait spots were noticed as $1.4 \%$, similar to earlier studies. In Israeli study [19], as $0.48 \%$ in Arabs and $0.11 \%$ in Jews, Japanese study (1986) [16] as $1.7 \%$, thai study (2013) [30] showed 0.3\%, U.S. study (2012) [31] as $2 \%$. Miniature Puberty was found to occur with $6.9 \%$ similar to earlier studies. Harlequin Color Change accounted to $0.6 \%$, was seen mainly in preterm neonates, none in post term babies. Cutismarmoratus was the another skin lesion with $0.8 \%$, mainly due to constriction of venules and capillaries and disappear with rewarming. Prevalence was more in preterm babies. Traumatic Lesions during delivery accounted to 31 cases, mainly associated with forceps delivery, included sub-conjunctival hemorrhage and cephalohematoma. Occurrence of hyperpigmentation of genitals, knuckle and pinna was not found commonly.

\section{Limitations of Study}

1. Ours is cross-sectional study, due to paucity of time. Longitudinal study would have been better, as neonates could be followed later on for atopic dermatitis and malignant changes of congenital menalocyticnevi.

2. Due to early discharge of mother (before 3 days), data on the occurrence of erythema toxicum neonatorum was affected.

\section{Conclusion}

1. In dark races, Mongolian spot is more common and in fairer races salmon path is common along with Epstein pearl.

2. Less occurrence of erythema toxicum neonatorum in our study is attributed to the fact that some of the newborns could'nt be observed till 3 days of age due to the early discharge of mother.

3. Patients developing erythema toxicumneo natorum, have chances of developing atopic dermatitis, so biannual follow up should be done in those cases.

4. Cases of congenital melanocytic nevi should be followed up closely to rule out chances of malignant transformation.

5. Fetal skin biopsy has crucial role in identifying the genetic skin diseases with reasonably high levels of safety and confidence.

Funding: Nil, Conflict of interest: None initiated. Permission from IRB: Yes

\section{References}

1. Behne M.J., Barry N. P., Hanson K. M., Aronchik I., Clegg R. W., Gratton E., Feingold K., Holleran W. M., Elias P.M., Mauro T. M: Neonatal Development of the stratum corneum $\mathrm{pH}$ gradient: Localization and mechanisms leading to Emergency of Optimal Barrier junction: The Journal of Investigative Dermatology 2003 June:120(6).

2. Darmstadt GL, Dinulos JG. Neonatal skin care. Pediatr Clin North Am. 2000 Aug;47(4):757-82.

3. Avery's Neonatology: Pathophysiology and management of the newborn, 6 th edition South Asian edition Chp 55, pg 1485-1505:Dermatologic conditions: James G.H. Dinulos and Gary L Darmstadt. 
4. Cetta F, Lambert GH, Ros SP. Newborn chemical exposure from over-the-counter skin care products. Clin Pediatr (Phila). 1991 May;30(5):286-9.

5. Holbrook KA, Smith LT, Elias S. Prenatal diagnosis of genetic skin disease using fetal skin biopsy samples. Arch Dermatol. 1993 Nov;129(11):1437-54.

6. Sybert VP, Holbrook KA, Levy M. Prenatal diagnosis of severe dermatologic diseases. Adv Dermatol. 1992;7:179-209; discussion 210.

7. Hoeger PH, Schreiner V, Klaassen IA, Enzmann CC, Friedrichs K, Bleck O. Epidermal barrier lipids in human vernix caseosa: corresponding ceramide pattern in vernix and fetal skin. Br J Dermatol. 2002 Feb;146(2):194-201.

8. Dohil MA, Baugh WP, Eichenfield LF. Vascular and pigmented birthmarks. Pediatr Clin North Am. 2000 Aug;47(4):783-812, v-vi.

9. PACHMAN DJ. Massive hemorrhage in the scalp of the newborn infant: hemorrhagic caput succedaneum. Pediatrics. 1962 Jun;29:907-10.

10. Haveri FT, Inamadar AC. A cross-sectional prospective study of cutaneous lesions in newborn. ISRN Dermatol. 2014 Jan 20;2014:360590. doi: 10.1155/2014/360590. eCollection 2014.

11. Sachdeva M, Kaur S, Nagpal M, Dewan SP. Cutaneous lesions in new born. Indian $\mathrm{J}$ Dermatol Venereol Leprol. 2002 Nov-Dec;68(6):334-7.

12. Nanda A, Kaur S, Bhakoo ON, Dhall K. Survey of cutaneous lesions in Indian newborns. Pediatr Dermatol. 1989 Mar;6(1):39-42.

13. Moosavi Z, Hosseini T. One-year survey of cutaneous lesions in 1000 consecutive Iranian newborns. Pediatr Dermatol. 2006 Jan-Feb;23(1):61-3.

14. Gokdemir G, Erdogan HK, Köşlü A, Baksu B. Cutaneous lesions in Turkish neonates born in a teaching hospital. Indian J Dermatol Venereol Leprol. 2009 Nov-Dec;75(6):638. doi: 10.4103/0378-6323. 57742.

15. Dash K, Grover S, Radhakrishnan S, Vani M. Clinico epidemiological study of cutaneous manifestations in the neonate. Indian $\mathbf{J}$ Dermatol Venereol Leprol. 2000 Jan-Feb;66(1):26-8.

16. Hidano A, Purwoko R, Jitsukawa $\mathrm{K}$,:Stastical survey of skin changes in Japanese neonates; Pediatric Dermatology:3(2),pp 140-144,1986.

17. Shih IH, Lin JY, Chen CH, Hong HS:A birthmark survey in 500 newborn : clinical observation in two northern Taiwan medical centre nurseries "Chang Gung Medical Journal”, vol 30,no 3,pp 220- 225,2007.

18. Ferahabas A, AkcakusM,Gunes T, Mistik S:Prevalence of cutaneous findings in hospitalized Neonates: A Prospective Observational Study; Pediatric Dermatology:26(2):139-142;2009

19. Kahana M, Feldman M, Abudi Z, Yurman S. The incidence of birthmarks in Israeli neonates. Int $\mathrm{J}$ Dermatol. 1995 Oct;34(10):704-6.

20. Rivers JK, Frederiksen PC, Dibdin C. A prevalence survey of dermatoses in the Australian neonate. J Am Acad Dermatol. 1990 Jul;23(1):77-81.

21. Jacobs AH, Walton RG. The incidence of birthmarks in the neonate. Pediatrics. 1976 Aug; 58 (2) : 218-22.

22. Osburn K, Schosser RH, Everett MA. Congenital pigmented and vascular lesions in newborn infants. J Am Acad Dermatol. 1987 Apr;16(4):788-92.

23. Lau JT, Ching RM. Mongolian spots in Chinese children. Am J Dis Child. 1982 Sep;136(9):863-4.

24. Shajari H, ShajariA,Sajadian N, Habiby M: The incidence of birthmarks in Iranian neonates “ActaMedicaIranica” vol 45,pp 424-426,2007.

25. PruksachatkunakomC,Duarte AM, Schanchner LA : Skin lesions in newborns; International Pediatrics vol14, no 1, pp 28-31, 1999.

26. DahiyatKA: Neonatal skin lesions in Jordan Study of consecutive 500 neonates at King Hussain Medical centre, Calicut Medical Journal:4(4) article el, 2006.

27. NobbayB, Chakrabarty N, Cutaneous manifestations in the newborn. Indian J Dermatol Venereol Leprol 1992;58:69-72. 
28. Karvonen SL, Vaajalahti P, Marenk M, Janas M, Kuokkanen K. Birthmarks in 4346 Finnish newborns. Acta Derm Venereol. 1992;72(1):55-7.

29. El-Moneim AA, El-Dawela RE. Survey of skin disorders in newborns: clinical observation in an Egyptian medical centre nursery. East Mediterr Health J. 2012 Jan;18(1):49-55.
30. Chaithirayanon S, Chunharas A. A survey of birthmarks and cutaneous skin lesions in newborns. J Med Assoc Thai. 2013 Jan;96 Suppl 1:S49-53.

31. Kanada KN, MerinMR, Munden A, Friedlander SF: A Prospective study of cutaneous findings in newborn in the US: correlatioin with race, ethnicity, and gestational status using updated classification and nomenclature:J Pediatr.2012 Aug;161(2):240-5.

\section{How to cite this article?}

Kurrey VK, Phuljhele S, Jain Y. To study the prevalence of cutaneous manifestationsin newborns and its correlation with defined maternal and neonatal factors. Int J Med Res Rev 2016;4 (6):956-963.doi: 10.17511/ijmrr.2016.i06.16. 